\title{
OPTIMALISASI LAYANAN PERPUSTAKAAN UNTUK PENINGKATAN MOTIVASI MINAT BACA DI MTS.N KALIANGKREK KABUPATEN MAGELANG
}

\begin{tabular}{|l|}
\hline - Diterima Mitra Bestari \\
(reviewer) tanggal 10 \\
Oktober 2019; \\
- Dikembalikan kepada \\
Penulis tanggal 14 \\
Oktober 2019; \\
- Hasil Revisi Diterima \\
Pengelola tanggal 17 \\
Oktober 2019 \\
\hline
\end{tabular}

\author{
Nursangadah \\ Widyaiswara Ahli Madya \\ Balai Diklat Keagamaan Semarang \\ e-mail: nur1964sangadah@gmail.com
}

\begin{abstract}
Abstrak
Tujuan penelitian ini: (1) mendiskripsikan ptimalisasi perpustakaan di MTs.N Kali angkrek Magelang (2) mendiskripsikan peningkatan motivasi minat baca siswa di MTs.N Kaliangkrek Magelang. Metode pengumpulan data dalam penelitian ini menggunakan teknik observasi, wawancara dan dokumentasi. Teknik analisis data yang digunakan yaitu pengumpulan data, reduksi data, penyajian data dan verifikasi/kesimpulan. Hasil dapat disimpulkan bahwa, (1) Optimalisasi layanan perpustakaan MTs.N Kaliangkrek Kab.Magelang ialah melakukan berbagai pengoptimalan perpustakaan yaitu dari segi pengelolaan perpustakaan diantaranya suasana ruang perpustakaan (ruang tempat/ruang baca yang luas, penataan rak buku yang rapi dan penambahan hiasan dinding), petugas perpustakaan yang profesional, pengadaan/penambahan koleksi buku/bahan pustaka, pelayanan sirkulasi dan tata tertib perpustakaan MTs.N Kaliangkrek Kab.Magelang. (2) Motivasi minat baca siswa di MTs.N Kaliangkrek Kab. Magelang, disamping menggunakan perpustakaan untuk menyalurkan minat dan kegemaran membaca, terdapat juga kegiatan pembelajarn disekolah yang berkaitan erat dengan motivasi minat baca siswa yaitu: penetapan kebijakan pengembangan program peningkatan motivasi minat baca dan penyediaan fasilitas
\end{abstract}

Kata Kunci: Layanan, Perpustakaan, Minat, Baca,

\section{A. PENDAHULUAN}

\section{Latar Belakang Masalah}

Secara umum perpustakaan

mempunyai fungsi sebagai suatu tempat yang kegiatannya meliputi penghimpunan, pengelolaan dan penyebarluasan (pelayanan) segala macam informasi, baik yang tercetak maupun yang terekam dalam berbagai media seperti buku, majalah, surat kabar, film, kaset, tape recorder, video, komputer, dan lain- lain. Semua koleksi sumber informasi tersebut disusun berdasarkan sistem tertentu dan dipergunakan untuk kepentingan belajar melalui kegiatan membaca dan mencari informasi bagi segenap masyarakat yang membutuhkan. Wafford tahun 2009 mendefinisikan perpustakaan sebagai salah satu organisasi sumber belajar yang menyimpan, mengelola, dan memberikan layanan bahan pustaka baik buku maupun non buku kepada masyarakat tertentu maupun masyarakat umum. Perpustakaan merupakan tempat 
untuk mengumpulkan, menyimpan, mengelola, dan mengatur koleksi bahan pustaka secara sistematis untuk digunakan oleh pemakai sebagai sumber informasi sekaligus sebagai sarana belajar yang menyenangkan.

Perpustakaan merupakan pusat interaksi siswa dengan buku, sehingga perpustakaan sangat penting dalam proses belajar. Kenyamanan dan kelengkapan koleksi buku adalah syarat mutlak untuk meningkatkan kemauan dan kemampuan belajar siswa. Sehingga, diperlukan pengelolaan perpustakaan yang serius mengenai penataan perpustakaan. Karena hal ini mempengaruhi minat siswa untuk belajar. Berbagai fasilitas dan layanan yang tersedia di perpustakaan termasuk bahan literatur, jurnal, dan majalah, hasil-hasil penelitian serta ada juga aktifitas kebudayaan. Pendidikan pada dasarnya usaha sadar untuk menumbuh kembangkan potensi sumber daya manusia peserta didik dengan cara mendorong dan menfasilitasi kegiatan belajar mereka.

Ruang baca merupakan ruang yang digunakan oleh pengguna atau pengunjung perpustakaan untuk membaca bahan pustaka. Ruang baca bukanlah sekedar ruangan untuk membaca, melainkan sebagai sarana perekaman informasi dari sumber ilmu agar lebih "khusyuk". Penempatan ruang baca pada umumnya berdekatan dengan koleksi, atau ruang koleksi dan ruang baca digabungkan dalam satu ruangan jika layanan yang dilakukan sistem terbuka. Fasilitas baca adalah perlengkapan perpustakaan yang disediakan di ruang baca untuk keperluan pengunjung perpustakaan seperti meja baca, kursi baca dan buku yang lengkap.

Menurut Bafadal tahun 2010 penataan ruang dan perlengkapan yang tersedia harus ditata dan dirawat dengan baik sehingga benar-benar menunjang penyelenggaraan perpustakaan sekolah secara efektif dan efisien. Keberadaan perpustakaan di lingkungan sekolah tidak akan ada artinya jika perpustakaan tidak ada yang mengunjungi baik siswa maupun guru. Untuk menghindari hal tersebut maka perlu bagi pengelola perpustakaan agar lebih memperhatikan dan mengelola layanan ruang baca diperpustakaan untuk membuat pembaca merasa nyaman berada di ruang baca perpustakaan tersebut. Dengan adanya ruang baca di perpustakaan diharapkan dapat meningkatkan motivasi siswa dalam membaca. Karena, dengan membaca dapat membuka jendela ilmu pengetahuan yang lebih luas, sehingga dapat melahirkan 
pendidikan yang berkualitas dan anak didik yang mampu beranalisis. Kemampuan analisis sangat dipengaruhi oleh membaca karena membaca dapat mengasah inteligensi, kecakapan berbahasa, berkomunikasi dan menulis.

Kondisi perpustakaan sekolah ditingkatkan dengan pemberdayaan pengelo la, sarana serta koleksi bahan pustaka yang tiap tahun selalu bertambah. Namun, semua itu hanya akan menjadi dilema, manakala perpustakaan sekolah tidak dikelola dengan baik. Terlebih lagi apabila suasana perpustakaan tersebut tidak menarik. Walaupun tidak ada yang mengingkari banyaknya ilmu pengetahuan yang dikandung oleh buku, sedangkan minat baca yang kurang, buku hanya menjadi tempat penimbunan atau gudang ilmu pengetahuan. Jangankan untuk membaca, sekedar singgah saja mungkin siswa sudah enggan sehingga eksistensi sebuah perpustakaan dianggap seperti ruang kosong dan fungsinya sebagai gudang ilmu menjadi terabaikan. Belum ada kondisi realita dan pemanfaatan perpustakaan di MTs.N Kaliangkrek Kabupaten Magelang.

Berangkat dari permasalahan yang ada di sekolah tersebut, maka peneliti tertarik untuk melakukan penelitian mengenai masalah tersebut dengan judul
“Optimalisasi Layanan Perpustakaan Untuk Peningkatan Motivasi Minat Membaca Siswa di MTs.N Kaliangkrek Kab.Magelang"

\section{Rumusan Masalah}

1. Bagaimana optimalisasi layanan perpustakaan untuk peningkatan motivasi minat baca di MTs.N Kaliangkrek Kab.Magelang?

2. Bagaimana peningkatan optimalisasi layanan perpustakaan untuk peningkatan motivasi minat baca siswa MTs.N Kaliangkrek Kab.Magelang?

\section{Tujuan Penulisan}

1. Mengetahui optimalisasi layanan perpustakaan untuk peningkatan motivasi minat baca di MTs.N Kaliangkrek Kab. Magelang

2. Mengetahui peningkatan optimalisasi layanan perpustakaan untuk peningkatan motivasi minat baca siswa MTs.N Kaliangkrek Kab. Magelang

\section{Manfaat penulisan}

1. Bagi peserta siswa: sebagai wacana untuk meningkatkan aktivitas dan membaca yang pada akhirnya akan dapat pula meningkatkan prestasi belajar;

2. Bagi warga sekolah : Untuk dasar sebagai masukan dalam menentukan kebijakan dan dalam 
mendorong peningkatan aktivitas membaca buku-buku perpustakaan agar dapat meningkatkan layanan perpustakaan;

3. Bagi MTsN: Khususnya perpustakaan MTs.N Kaliangkrek Kab. Magelang dapat digunakan sebagai bahan masukan pengembangan koleksi yang relevan dengan meningkatkan layanan perpustakaan;

4. Bagi peneliti : menambah pengalaman dalam melakukan penelitian.

\section{Metode Penelitian}

Pendekatan penelitian adalah kualitatif deskriptif artinya akan banyak menggunakan gambaran melalui suatu penjelasan yang terarah dan diharapkan akan memperoleh suatu hasil atau kesimpulan tentang masalah yang diteliti. Pengumpulan data menggunakan teknik observasi, wawancara dan observasi. Dalam menganalisis data, peneliti menggunakan analisis deskriptif, yaitu pengumpulan data, reduksi data, penyajian data dan verifikasi/kesimpulan.

\section{Kajian Teori}

Perpustkaan adalah institusi pengelola koleksi karya tulis, karya cetak, atau karya rekam dengan sistem yang baku guna memenuhi kebutuhan pendidikan, penelitian, pelestarian informasi dan rekereasi. Perpustakaan terbagi menjadi beberapa bidang eperti perpustkaan nasional, badan perpustkaan nasiona, badan perpustakaan daerah, peprustkaan pribadi.

Pelayanan adalah bentuk pemberian yang diberikan oleh produsen baik terhadap pelayanan baranag yang di produksi maupun terhadap jasa yang ditawarkan guna memperoleh minat konsumen, dengan demikian pelayanan mempengaruhi minta konsumen.

Optimalisasi pengelola perpustakaan harus di dukung oleh pengelola perpustakaan yang profesional dan modern oleh pihak perguruan tinggi. Ada beberapa aspek yang diperhatikan. Peratama, dengan pengelola perpustakaan yang lebih profesional. Kedua, pengembangan perpustakaan dengan fasilitas ynng memamdai.

\section{B. PEMBAHASAN DAN HASIL ANALISA}

Optimalisasi layanan perpustakaan di mtsn kali angkrek kab. Magelang

Melalui perpustakaan sekolah para siswa juga dapat mencari informasi dan menambah pengetahuanya selain dari pelajaran yang diterima di kelas. Karena di perpustakaan menyediakan buku-buku 
pelajaran, ilmu pengetahuan dan lain sebagainya, Untuk mencapai tujuan yang sebenarnya yakni optimalisasi layanan perpustakaan sebagai salah satu sarana motivasi minat baca siswa, maka perpustakaan MTs.N Kaliangkrek Kab. Magelang melakukan berbagai pengoptimalan perpustakaan dari segi pengelolaan perpustakaan, yaitu dari suasana ruang perpustakaan (ruang tempat/ruang baca, penataan rak buku dan penambahan hiasan dinding), petugas perpustakaan, pengadaan/ penambahan koleksi buku/ bahan pustaka, pelayanan sirkulasi dan tata tertib perpustakaan MTs.N Kaliangkrek Kab. Magelang.

Berdasarkan temuan peneliti perpustakaan MTs.N Kaliangkrek memiliki prasarana berupa ruangan perpustakaan dengan ukuran luas $12 \times 7$ meter, rak buku, almari, serta meja sebanyak 4 unit. Dengan ukuran perpustakaan besar, denah perpustakaan menjadi rapi sehingga siswa yang datang kesana menjadi nyaman. Ditambah dengan koleksi buku yang berjumlah 11ribu buku didalamnya 3ribu buku fiksi dan non fiksi, 7ribu buku cerita dan teks buku mebuat siswa tertarik untuk datang ke perpustakaan dan juga dihiasi dengan hiasan-hiasan dinding yang menarik Pustakawan yang ada di perpustakaan MTs.N Kaliangkrek
Kab. Magelang cukup berpengalaman dalam hal.mengelola perpustakaan. Yang mana pustakawan tersebut sudah 3 tahun menjabat sebagai kepala perpustakaan, beliau juga mengenyam pendidikan S1. Tentunya telah mengenyam pendidikan yang cukup dan mengerti tentang bagaimana cara mengelola perpustakaan yang baik sehingga perpustakaan dapat berjalan sebagaimana fungsinya.

Hasil wawancara peneliti dengan pustakawan diperoleh kesimpulan yaitu bahwa usaha yang dilakukan oleh pihak perpustakaan untuk bisa memanfaatkan perpustakaan sebagai sarana dalam meningkatkan minat baca siswa diantaranya memberikan pelayanan yang baik dan bekerja sama dengan guruguru untuk bisa menggunakan perpustakaan dalam proses belajar mengajar.

Hasil pengamatan peneliti dapat diambil kesimpulan bahwa kondisi perpustkaan MTs.N Kaliangkrek Kab. Magelang cukup memadai dan memenuhi syarat sebagai sarana pendidikan, yang mana syarat utama perpustakaan adalah adanya gedung(ruangan), koleksi bahan pustaka, perlengkapan dan perabot, mata anggaran atau sumber pembiayaan serta tenaga kerja serta koleksi buku yang dimiliki 
MTs.N Kaliangkrek Kab. Magelang ini cukup lengkap.

$$
\text { Pelayanan sistem pelayanan }
$$
perpustakaan sekolah yang terdiri dari dua macam sistem yakni sistem terbuka dan sistem tertutup ini biasanya didasarkan atas beberapa pertimbangan misalnya keadaan ruangan, besar kecilnya koleksi dan banyak sedikitnya perpustakaan.

Berdasarkan temuan peneliti, tata cara peminjaman dan pengembalian buku diperpustakaan MTsN Kaliangkrek Kab. Magelang dianggap mudah bagi siswa. Hal itu dapat dilihat dari siswa siswi yang berkunjung sudah mengetahui tata cara peminjaman dan pengembalian serta dapat melakukan tanpa mengalami kesulitan.

Optimalisasi layanan perpustakaan sekolah dalam meningkatkan motivasi minat baca siswa dapat dilihat dari daftar hadir kujungan siswa ke perpustakaan dan daftar peminjaman buku siswa. Hal ini dapat dilihat bahwa setiap harinya di perpustakaan MTs.N Kaliangkrek Kab. Magelang ini tidak sepi dari pengunjung. Ini menandakan bahwa dengan adanya optimalisasi layanan perpustakaan di sekolah sangat membantu dalam meningkatkan motivasi minat baca

\section{Motivasi Minat Baca Siswa di MTs.N Kaliangkrek Kab. Magelang}

Kegiatan membaca akan menjadi sebuah kebutuhan apabila kita selalu ingin mengetahui isi dari suatu bacaan. Sebanyak apapun bahan pustaka yang dimiliki perpustakaan, apabila minat baca siswa rendah maka bahan pustaka yang dimiliki perpustakaan tidak akan berguna. Dan sebaliknya apabila bahan pustaka yang dimiliki perpustakaan sedikit akan tetapi minat baca baca siswa itu sendiri tinggi maka bahan pustaka yang dimiliki perpustakaan akan sangat bermanfaat dan berguna Sehingga manfaat dari perpustakaan itu sendiri tergantung dengat minat dan motivasi mereka untuk membaca siswa itu sendiri. Maka dari itu agar perpustakaan sekolah dapat dimanfaatkan secara maksimal , minat dan motivasi membaca siswa itu perlu ditingkatkan dan ditumbuh kembangkan.

MTs.N Kaliangkrek Kab. Magelang motivasi minat baca siswa sangat bagus, misalnya terdapat kegiatan pembelajaran di sekolah yang erat kaitanya dengan minat baca seperti lomba pidato, membaca puisi, membuat kliping, pembuatan mading sekolah. Penggunaan perpustakaan untuk menyalurkan minat dan kegemaran membaca, terdapat juga kegiatan pembelajaran di 
sekolah yang berkaitan erat dengan minat baca siswa, misalnya: pemberian tugas dari guru yang berhubungan dengan minat membaca siswa seperti: membuat kliping, mading sekolah, dan lain sebagainya Untuk meningkatkan minat baca siswa maka banyak usaha yang dilakukan oleh pihak sekolah diantaranya terdapat kegiatan pembelajaran disekolah yang erat kaitanya dengan minat membaca, misalnya: mengikuti lomba pidato, puisi atau prosa, pemberian tugas dari guru yang berhubungan dengan minat baca siswa seperti: membuat kliping, mading sekolah dan lail sebagainya.

Pernyataan yang diperoleh bahwa motivasi minat baca tiap siswa di MTs.N Kaliangkrek Kab. Magelang sangatlah bervariasi . Banyak faktor-faktor yang mempengaruhi motivasi minat baca yakni faktor pendukung dan penghambat. Dalam kaitanya dengan meningkatkan minat membaca siswa di sekolah maka faktor pendukung sarana perpustakaan sekolah juga sangat mempengaruhi salah satunya yaitu tersedianya perpustakaan yang memadai.

Dengan demikian untuk meningkatkan minat baca siswa, maka seorang guru harus bisa memanfaatkan sarana prasarana yang ada di sekolah, salah satunya adalah perpustakaan sekolah. Dengan mengajak siswa ke perpustakaan sekolah dalam menciptakan suasana belajar yang tidak membosankan. Meningkatkan minat baca dan prestasi belajar siswa semakin tinggi minat baca pada siswa maka semakin tinggi pada hasil belajar yang diterimanya sehingga diharapkan dapat mencapai tujuan belajar yang optimal

\section{PENUTUP}

\section{Simpulan}

1. Dengan melihat kondisi sarana dan prasarana yang ada di MTs.N Kaliangkrek Kab. Magelang salah satunya adalah perpustakaan, yang mana optimalisasi layanan perpustakaan di MTs.N Kaliangkrek Kab. Magelang banyak membantu dalam meningkatkan motivasi minat baca para siswanya. Untuk mencapai tujuan yang sebenarnya yakni optimalisasi layanan perpustakaan untuk meningkatkan motivasi minat baca siswa, maka perpustakaan MTs.N Kaliangkrek Kab. Magelang melakukan berbagai pengoptimalan perpustakaan dari segi pengelolaan perpustakaan yaitu dari suasana ruang perpustakaan(ruang/tempat, rak buku, dan penambahan hiasan dinding);

2. Di MTs.N Kaliangkrek Kab. Magelang motivasi minat baca siswa sangat 
bagus, misalnya disamping menggunakan perpustakaan untuk menyalurkan minat dan kegemaran membaca, terdapat juga kegiatan pembelajaran disekolah yang berkaitan erat dengan minat baca siswa yaitu mengikuti lomba pidato, pembacaan puisi atau prosa, pemberian tugas dari guru yang berhubungan dengan minat baca seperti: membuat kliping, mading sekolah, dan lain sebagainya.

\section{Rekomendasi}

1. Bagi Guru, hendaknya harus lebih bisa memotivasi siswa untuk meningkatkan minat baca siswa agar siswa lebih giat lagi untuk pergi keperpustakaan;

2. Bagi peneliiti selanjutnya, perlu diperhatikan bahwa hasil analisis tentang penelitian optimalisasi layanan perputakaan untuk meningkatkan motivasi minat baca siswa di MTs.N Kaliangkrek Kab. Magelang ini masih belum bisa dikatakan final, sebab masih banyak kekurangan didalamnya;

3. Bagi BDK Semarang, perlu diadakanya kegitan diklat terkait dengan topi optimalisasi layana pepustakaan.

\section{DAFTAR PUSTAKA}

Bafadal. (2009). Pengelolaan Perpustakaan Sekolah. Malang: Bumi Aksara.

Memans. (2008) .Layanan Perpustakaan Sekolah Dan Jasa Rujukan. http://memans.wordpress.com/200 8/06/02/LayananPerpustakaSekolah-dan-jasa-rujukan/> 13 Januari 2008.

Noerhayati, Soedibyo. (1987). Pengelolaan Perpustakaan. Bandung:P.T Alumni,

Pawit, M. Yusuf. 2007. Pedoman Penyelenggaraan Perpustakaan Sekolah,. Jakarta: Kencana.

Perpustakaan Nasional RI. 2006. Pedoman Umum Penyelenggaraan Perpustakaan Sekolah. Jakarta : Perpustakaan Nasional RI.

Suharsimi Arikunto. 1998. Prosedur Penelitian. Jakarta: Rineka Cipta.

Suhendar Yaya, M.yusuf Pawit. (2007). Pedoman Penyelenggaraan Perpustakaan Sekolah. Jakarta: Prenada Media Group.Soeatminah. 1992.

Sutarno NS. (2003). Perpustakaan dan Masyarakat, edisi 1. Jakarta: Yayasan Obor Indonesia. 